\title{
Modeling co-dependent choice of workplace, residence and commuting mode using an error component mixed logit model
}

\author{
Jia Guo ${ }^{1} \cdot$ Tao Feng $^{1}$ (D) Harry J. P. Timmermans ${ }^{1,2}$ (D)
}

Published online: 19 September 2018

(c) The Author(s) 2018

\begin{abstract}
This paper develops an error component mixed logit model to analyze the multi-dimensional residential, work and transportation mode choice. It expanse previous studies based on life-trajectory theory which predominantly only considered two life domains. In contributing to this emerging field of research, we design an integrated pivoted stated choice experiment considering the multi-dimensional choice of job, residence and transportation mode for the journey to work. The results of the estimated error component mixed logit model with panel effects indicate that most selected attributes of the residential environment, job profile and transportation mode are significantly related to individual differences in multidimensional choices. Moreover, the estimation of various sources of unobserved heterogeneity signals significant unobserved heterogeneity in selected taste parameters, and choice dependent heteroscedasticity in error component variance.
\end{abstract}

Keywords Co-dependent location $\cdot$ Multidimensional choice $\cdot$ Pivoted stated choice experiment $\cdot$ Error component logit model $\cdot$ Panel data $\cdot$ Heterogeneity

\section{Introduction}

The transportation literature is well endowed with models of transportation mode choice (e.g. Quarmby 1967; Meyer et al. 1978; Grava 2003; Rodriguez and Joo 2004; Meixell and Norbis 2008; Heinen et al. 2013). The most common way of modeling transportation mode choice is to assume that a set of vehicle and trip attributes generates a certain amount of

Tao Feng

t.feng@tue.nl

Jia Guo

j.guo@tue.nl

Harry J. P. Timmermans

h.j.p.timmermans@tue.nl

1 Urban Planning Group, Department of the Built Environment, Eindhoven University of Technology, PO Box 513, 5600MB Eindhoven, The Netherlands

2 Department of Air Transportation Management, NUAA, Jiangjun Avenue, Jiangning District, Nanjing 211106, China 
utility for travellers of a particular socio-economic profile who are assumed to choose the transportation mode that maximizes their utility. Sometimes, taste variation is allowed by assuming the taste parameters exhibit a particular distribution (e.g., Bhat 2000; Paulssen et al. 2014).

This common restriction to vehicle and trip attributes has some important limitations. When some time ago, major transit oriented development projects in the Netherlands decreased travel times by public transportation, prevailing models predicted a shift in transportation mode choice to the train. In reality, however, a substantial share of the workers decided to move further away from their workplace to enjoy a larger, relatively cheap house, located in a more rural area without increasing their commute travel times. The transportation mode choice models did and could not predict this response to the development scheme, simply because the transportation mode choice model lacked the relevant variables and the necessary larger perspective.

The point is that life trajectories are critical in understanding daily activity-travel patterns and underlying decisions. People hold a series of aspirations related to different life domains, among which job and housing careers constitute key domains. The decision to move to the next stage in the careers that make up the life trajectories is often made if certain constraints (e.g. budget, travel time constraints) are lifted or if changes in other careers increase the need for change in the domain of interest. The example above illustrates that as travel times constraints are relaxed, some households will take the opportunity to move closer to the ultimate life trajectory housing aspirations by moving house without the need to deal with longer travel time commutes.

Recently, the view has re-emerged that people's decisions with respect to different lifedomains should be treated as a 'bundle' choice. In that sense, the job (location) choice, residential choice, commuting times, transportation mode choice and underlying vehicle possession are strongly interdependent. Rather than maximizing the utility of each of these choice facets separately and independently, it is more realistic to assume that individuals/ households consider the multidimensionality and maximize the utility of the multidimensional profile (or apply another choice mechanism to the multidimensional profile), against the background of their life-course trajectories. Because we do not observe people moving house or changing jobs many times, we should account for some possible inertia is response times.

To date, relatively little work has been reported about people's preferences for interdependent long-term residential, job choice, and short-term commuting transportation mode choice. Moreover, existing work tends to be based on retrospective survey data. While such data reflect real historical events and decisions, a disadvantage is that the data controls the researcher rather than the researcher controlling the data (properties). Thus, it would be relevant to complement these studies with studies based on stated choice data to obtain a more fundamental understanding of multidimensional choice behavior as it relates to the choice of job, residence and transportation mode for the commute trip.

Thus, the objective of this study is twofold. First, based on the contention that individuals and households consider these three dimensions, a stated choice experiment was designed to mimic the multidimensional choice behavior of interest and estimate a model of multidimensional choice concerned with residence, job and transportation mode for the commute trip. Second, this study further examines various sources of unobserved heterogeneity in the multidimensional choice behavior addressed in this study.

The remainder of this paper is organized as follows: In "Literature review" section, we review the literature on the multidimensional choice behavior related to housing, job and transportation. "Survey and experimental design" section presents the stated choice 
experiment that is based on a pivoted D-efficient design. A brief description of the data is also presented in this section. Next, the multi-dimensional choice model based on the error component mixed logit model is presented in "Model formulation" section. Then, the results of the model estimation are presented in "Analysis and results" section. Conclusions and a discussion of future research directions are presented in the last section.

\section{Literature review}

The transportation literature is extremely rich of transportation mode choice models. The vast majority of these models assume that individuals maximize the utility they derive from the attributes of the transportation mode and trip characteristics. In the context of the topic of this paper, these models thus involve a unidimensional choice problem. Consequently, any predictions, based on these models, are necessarily refined to vehicle and trip characteristics. This is not a problem if the management or policy issue concerns vehicles and trip attributes, and does not affect space-time prisms of individuals. However, if the policy would open up new opportunities, individuals may reconsider the intricate relationship between residence, job and transportation mode.

As argued in Van der Waerden and Timmermans (2003), other key life domains, such as residential and work relocation, may induce changes in travel behavior. During the last decades, many studies have emphasized the simultaneous nature of the choice of residential mobility and commuting mode (e.g., Desalvo and Huq 2005; Bhat and Guo 2007; Salon 2009; Pinjari et al. 2011; Guerra 2015). As an example, Handy et al. (2005) found significant changes in travel mode and car travel distances after residential relocation. In the work domain, key events such as first-time entry into the labor market, job change, income change and retirement were found to influence travel mobility change (e.g., Dargay 2001; Dargay and Hanly 2007; Scheiner and Holz-Rau 2013). In turn, commuting mode preference also influences residential and/or work location choice. For example, commuters by public transportation may find the egress time important and consciously choose to live/work near a transit station (Bhat and Guo 2007). People living in sprawling areas rely more on cars to conduct their daily activities (Khattak and Rodriguez 2005; Schwanen and Mokhtarian 2005a, b). Additionally, increasing travel time may trigger people to reconsider and possibly change their residence or job. Ettema (2010) pointed out that excess commute distance may prompt the relocation process and trigger people move to a new dwelling; likewise, longer commuting time or activity duration may accelerate relocation decisions (Rashidi et al. 2011). This emphasis on the interdependency has led to the joint choice modeling of residential/work location and commuting behavior (e.g., Kim et al. 2003; Ng 2008).

However, although the interdependency between residential and job choice decisions and transportation mode choice has been acknowledged, most empirical studies considered only two choice dimensions. Literature on the joint choice of all three dimensions is relatively scarce. Several decades ago, Lerman (1976) developed a multinomial logit model that combined multiple dimensions (residential location, automobile ownership, and commute mode choice). Rich and Nielsen (2001) presented a micro-econometric model for forecasting long-term travel demand considering residential location, house type and choice of work location. Salon (2006) explored the relationship between the transportation and land use system in New York City by modeling a multinomial logit model of the joint choices of residential location, car ownership, and commute mode of New Yorkers. 
Likewise, using data from the San Francisco Bay Area, Pinjari et al. (2011) formulated a joint model of residential location, car ownership, bicycle ownership, and commute tour mode choice. They found that these aspects are interrelated and one choice dimension is not exogenous to the others, but endogenous to the system as a whole. In another publication, Paleti et al. (2012) developed an integrated joint model of six different choice dimensions: residential location, work location, commute distance, household vehicle ownership, commuting mode and number of stops of commute trips.

Although these simultaneous choice models consider long-term decisions and shortterm decisions as an integrated choice, unfortunately, only few attributes were taken into account. Consequently, these studies perhaps oversimplified the choice problem. Thus, for the purpose of our research, we selected relatively many influential factors to mimic the complexity of the interdependency of residential, job and work commute transportation mode choice in reality.

Furthermore, because a considerable amount of observed and unobserved preference heterogeneity normally exists in multi-dimensional choice behavior, several error components are added to the conventional multidimensional multinomial logit model. The current study contributes to the literature in further understanding the joint decision of long-term mobility regarding house, job and transportation using the data collected through a stated choice experiment. First, we assume that taste differences in part depend on observed socio-demographic variables and in part reflect pure error. To incorporate this assumption, we estimate covariate-dependent effects to account for heterogeneity around the mean of taste parameter distributions, following Train (2003), and Hensher and Greene (2003). Second, to allow for the possibility that ubobserved preferences for transportation modes depend on long-term choice behavior, long-term choice specific error components are identified and the variance of these error components is estimated through parameterisation of their heteroscedasticity (Hensher and Greene 2003). Thus, we estimate an error component mixed logit model to identify random and systematic long-term choice specific heterogeneity. As an extension of the standard mixed logit model, this error component approach includes parameter estimates for latent error component effects (Greene and Hensher 2007). Specifically, the error component consists of IID and non-IID components, and the non-IID component part associates the unobserved variance nests with sociodemographic characteristics (gender, income and numbers of workers in the households).

\section{Survey and experimental design}

\section{Experimental design}

A stated preference experiment was designed to measure the preferences for multi-dimensional residential choice, job choice and transportation mode choice behavior. In total, nineteen attributes were selected for the choice experiment (Table 1). Several transportation researchers have expressed concerns about such a large number of attributes. While we do not wish to deny that large experimental design may induce unreliable responses, simple designs with just a few attributes may oversimplify the nature of the choice problem and therefore be less useful. The aim of the experimental design should be to mimic the complexity of the decision-making process under investigation in the real world, while controlling as much as possible for experimental artifacts that may jeopardize the reliability and validity of the experiment. 
Table 1 Attributes of house, job and transportation mode

\begin{tabular}{|c|c|c|}
\hline Name & Attribute & Attribute level \\
\hline \multirow[t]{7}{*}{ Residence } & Tenure & Rent, Buy \\
\hline & Cost (yuan/ month) & $500,1600,2200,3800$ \\
\hline & Size $\left(\mathrm{m}^{2}\right)$ & $30,65,90,125$ \\
\hline & Distance to metro station & $\begin{array}{l}-75 \%,-25 \%, 25 \%, 75 \% \text { change from the current } \\
\text { situation }\end{array}$ \\
\hline & Distance to bus stop & $\begin{array}{l}-75 \%,-25 \%, 25 \%, 75 \% \text { change from the current } \\
\text { situation }\end{array}$ \\
\hline & Distance to shopping mall & $\begin{array}{l}-75 \%,-25 \%, 25 \%, 75 \% \text { change from the current } \\
\text { situation }\end{array}$ \\
\hline & Home location & Central city, Surrounding area \\
\hline \multirow[t]{7}{*}{ Work } & Work type & Government, Institution, Enterprise, Self-employed \\
\hline & Flexibility & Yes, No \\
\hline & Salary (yuan/year) & $30 \mathrm{k}, 80 \mathrm{k}, 130 \mathrm{k}, 200 \mathrm{k}$ \\
\hline & Work environment & Very good, Good, Poor, Very poor \\
\hline & Colleague relationship & Very good, Good, Poor, Very poor \\
\hline & Easy to find a similar job & Yes, No \\
\hline & Work location & Central city, Surrounding area \\
\hline \multicolumn{3}{|c|}{ Transportation mode } \\
\hline \multirow[t]{3}{*}{ Car } & Travel cost (yuan) & $1.4,7,12.6,21$ \\
\hline & Travel time (min) & $4.5,18,31.5,45$ \\
\hline & Congestion time (min) & $\begin{array}{l}-75 \%,-25 \%, 25 \%, 75 \% \text { change from the current } \\
\text { situation }\end{array}$ \\
\hline \multirow[t]{4}{*}{ Metro } & Travel cost (yuan) & 2,4 \\
\hline & Travel time (min) & $5,20,35,50$ \\
\hline & Out-of-vehicle time (min) & $10,20,30,40$ \\
\hline & Have seats or not & Yes, No \\
\hline \multirow[t]{5}{*}{ Bus } & Travel cost (yuan) & 1,2 \\
\hline & Travel time (min) & $8,29,50,71$ \\
\hline & Out-of-vehicle time (min) & $5,10,15,20$ \\
\hline & Congestion time (min) & $\begin{array}{l}-75 \%,-25 \%, 25 \%, 75 \% \text { change from the current } \\
\text { situation }\end{array}$ \\
\hline & Have seats or not & Yes, No \\
\hline Bike & Travel time (min) & $9,54,84,120$ \\
\hline Walk & Travel time (min) & $30,144,252,360$ \\
\hline
\end{tabular}

Without specifying a particular causality in the dynamics, we told respondents that new job and residential opportunities occur regularly and that properties of work commute trips may change. They were informed that we were interested if under such circumstances, they would change their current house or job and which transportation mode they would then choose. Respondents were explained before making a choice so that they can take into account residential, work and transportation modes simultaneously in the choice experiment.

It should be noted that the single choice of transportation mode given residential and job attributes was not considered, neither the case of changing house and job 
simultaneously. The former, discussed already in a large body of transportation literature, is not the focus of the current study. However, we specifically examine the longterm mobility decision and treat the transportation mode choice a bundled decision with changing house or changing job. Changing transportation mode only given a certain situation of residence and job is considered a short-term decision. The latter option (changing both house and job), on the other hand, may require much mental processing from the people and the response could be unreliable without giving a proper setting of life contexts. Moreover, including these two options could make the choice experiment over complicated. Thus, the choice of changing transportation mode only and the option of changing both residential and work mobility were not considered.

The attributes included in the experiment were mainly drawn from the relevant literature in urban geography, urban sociology, and transportation (e.g., Louviere and Timmermans 1990; Timmermans et al. 1992; Van Ommeren 1999; Bagley et al. 2002; Walker and Li 2007; Ettema 2010; Schirmer et al. 2014; Balbontin et al. 2015; Tran et al. 2016). For the residential dimension, 2 two-level attributes and 5 four-level attributes were considered. These attributes include various attributes of the house (rent or buy, monthly costs, house size), location and neighbourhood characteristics (accessibility of metro station, bus station, shopping center), and residential location (city vs suburban). For the work dimension 2 two-level and 5 four-level attributes were used in the experiment: work type, flexibility of the work schedule, income, work environment, relationship with co-workers, the ease of finding a similar job and job location. The transportation mode dimension included five attributes: travel cost, travel time, out-ofvehicle time, congestion time and having seats or not. The attributes and their levels are shown in Table 1.

In order to better capture the effects of the selected attributes, we created a pivoted stated choice experimental design, which generates change relative to the current status of the respondents. Pivoting allows estimating choice models that include constraints on the choice probabilities and explicitly consider changes in attribute levels. Five attributes (distance to the metro station, bus station and shopping centre; congestion time by auto and bus) were considered as the pivoted attributes. Four levels $(-75 \%,-25 \%, 25 \%, 75 \%$ difference) were set using the personally experienced situation as the reference. Consequently, the hypothetical profiles are more realistic to specific respondents.

Because the profiles depend on the current situation of the respondents, they need to be generated during the survey completion process. Therefore, we used a Web-based survey system (Pauline, designed by our group), which offers many features especially related to the design and implementation of stated choice experiments. We dealt with the large numbers of attributes by designing two separate experiments; one for the residence-work dimension and another for the transportation dimension, and randomly paired these two designs. The first design involved a $4^{9} \times 2^{5}$ design and the second design involved a combination design (car: $4^{3} \times 2$, metro: $4^{2} \times 2^{2}$, bus: $4^{3} \times 2^{2}$, bike and walk $4^{1}$ ). Each design involved 128 profiles, which were randomly paired, creating $128 \times 128=16,384$ choice sets. Eight profiles were selected at random for each respondent.

As shown in Fig. 1, the choice task includes eleven labelled alternatives: three long term decisions (status quo, move house or change job), and for the latter two options, the choice among five transportation modes. Respondents were told that at any moment in time they more become aware of a new job opportunity and a vacant house. They were asked whether they would change job, move house or do not take any action if faced with these options. If they move house or change job, they should also indicate which transportation mode they would choose for the commute trip. 


\begin{tabular}{|c|c|c|c|c|c|c|c|c|c|c|c|}
\hline & Current Situation & \multicolumn{5}{|c|}{ Move House } & \multicolumn{5}{|c|}{ Change Job } \\
\hline Tenure & Buy & \multicolumn{5}{|c|}{ Rent } & \multirow{7}{*}{\multicolumn{5}{|c|}{ Your current house }} \\
\hline Cost (yuan/month) & 3800 & \multicolumn{5}{|c|}{600} & & & & & \\
\hline Size $\left(m^{2}\right)$ & 80 & \multicolumn{5}{|c|}{65} & & & & & \\
\hline Distance to the metro station $(\mathrm{km})$ & 0.3 & \multicolumn{5}{|c|}{2.0} & & & & & \\
\hline Distance to the bus stop $(\mathrm{km})$ & 0.2 & \multicolumn{5}{|c|}{1.0} & & & & & \\
\hline Distance to the shopping mall $(\mathrm{km})$ & 2 & \multirow{2}{*}{\multicolumn{5}{|c|}{$\begin{array}{c}1.25 \\
\text { Central City }\end{array}$}} & & & & & \\
\hline Home Location & Central City & & & & & & & & & & \\
\hline Type of company & Goverment & \multirow{7}{*}{\multicolumn{5}{|c|}{ Your current job }} & \multicolumn{5}{|c|}{ Self-employed } \\
\hline Flexibility & Yes & & & & & & \multicolumn{5}{|c|}{ No } \\
\hline Salary (yuan/year) & $8 w$ & & & & & & \multicolumn{5}{|c|}{$18 w$} \\
\hline Working environment & Not good & & & & & & \multicolumn{5}{|c|}{ Good } \\
\hline Co-worker Relationship & Good & & & & & & \multicolumn{5}{|c|}{ Not good } \\
\hline Easy to find a similar job & Yes & & & & & & \multirow{2}{*}{\multicolumn{5}{|c|}{$\begin{array}{c}\text { No } \\
\text { Surronding Area }\end{array}$}} \\
\hline Work Location & Central City & & & & & & & & & & \\
\hline Travel Mode & Bus & Car & Metro & Bus & Bike & Walk & Car & Metro & Bus & Bike & Walk \\
\hline Cost (yuan/time) & 1 & 10 & 2 & 4 & & & 40 & 4 & 1 & & \\
\hline Travel Time ( $\mathrm{min}$ ) & 40 & 7.5 & 7.5 & 15 & 7.5 & 20 & 30 & 30 & 25 & 30 & 5 \\
\hline Out-of Time ( $\mathrm{min}$ ) & 5 & & 40 & 40 & & & & 20 & 40 & & \\
\hline Congestion Time ( $\mathrm{min}$ ) & 20 & 7.5 & & 7.5 & & & 7.5 & & 22.5 & & \\
\hline Have seats or not & No & & Yes & No & & & & No & Yes & & \\
\hline Your Choice: & & & & & & & & $\sqrt{ }$ & & & \\
\hline
\end{tabular}

Fig. 1 The pivoted stated choice design

\section{Data analysis}

The data was collected in Shenyang, China, in 2016. Respondents were selected at random from five main districts in the central city and four other districts in the surrounding, new development areas. In our survey, respondents were asked to report their current residential situation, work characteristics, and travel behaviour, as well as personal and household socio-demographic characteristics. Considering the aim of the study, we only interviewed respondents who had a job. The sample consists of 401 respondents and 3208 observations for model estimation.

Table 2 presents the descriptive statistics of the main socio-demographic variables and other characteristics of the sample. It shows that gender is almost equally distributed. More than half of the respondents live alone $(54.4 \%) ; 63.8 \%$ live in the city center, while $36.2 \%$ live in the suburbs. Similarly, $65.3 \%$ of the respondents are employed in the central city, $34.7 \%$ work in the suburbs or other cities. As for commuting, $52 \%$ of the respondents have at least one car in their household. However, public transportation still dominates the transportation modes in our survey. $26.4 \%$ of the respondents drives to work, while $24.4 \%$ uses slow mode (bicycle or walk), implying that almost half of the respondents depend on/use public transportation.

\section{Model formulation}

To reflect the structure of the collected data, and incorporate different sources of heterogeneity, we formulated an error component mixed logit model. The model follows the principles of the approach suggested in Greene and Hensher (2007). Assume that individual $n$ faces the choice among multidimensional alternatives in choice situation $t$. The multidimensionality of the alternatives relates to the residential environment, job and a set of transportation modes focusing on the work commute. Individuals are assumed to derive from these multidimensional profiles a certain utility. The utility of alternative 
Table 2 Socio-demographic characteristics of respondents

\begin{tabular}{|c|c|c|c|}
\hline Variable & Classification & \# of cases & Percentage \\
\hline \multirow[t]{2}{*}{ Gender } & Male & 195 & 48.6 \\
\hline & Female & 206 & 51.4 \\
\hline \multirow[t]{2}{*}{ Age } & $18-40$ & 281 & 70.0 \\
\hline & $>40$ & 120 & 30.0 \\
\hline \multirow[t]{3}{*}{ Marital status } & Couple with children & 145 & 36.2 \\
\hline & Couple without children & 38 & 9.5 \\
\hline & Single & 218 & 54.4 \\
\hline \multirow[t]{2}{*}{ Number of workers } & Dual-earn workers & 240 & 59.9 \\
\hline & Single worker & 161 & 40.1 \\
\hline \multirow[t]{2}{*}{ Annual income } & $<60,000$ & 243 & 60.6 \\
\hline & $\geq 60,000$ & 158 & 39.4 \\
\hline \multirow[t]{2}{*}{ Tenure } & Buy & 337 & 84.0 \\
\hline & Rent & 64 & 16.0 \\
\hline \multirow[t]{2}{*}{ Home location } & Central city & 256 & 63.8 \\
\hline & Surrouding area & 145 & 36.2 \\
\hline \multirow[t]{4}{*}{ Work type } & Government & 35 & 8.7 \\
\hline & Public institutions & 74 & 18.5 \\
\hline & Joint venture, private firms & 201 & 50.1 \\
\hline & Self-employed & 91 & 22.7 \\
\hline \multirow[t]{2}{*}{ Work location } & Central city & 262 & 65.3 \\
\hline & Surrouding area & 139 & 34.7 \\
\hline \multirow[t]{6}{*}{ Commute mode } & Car & 106 & 26.4 \\
\hline & Metro & 65 & 16.2 \\
\hline & Bus & 96 & 23.9 \\
\hline & Shuttle & 32 & 8.0 \\
\hline & Bike & 75 & 18.7 \\
\hline & Walk & 27 & 6.7 \\
\hline
\end{tabular}

$i$ is assumed to be stochastic and consists of a deterministic utility, $V_{n i t}$, and a random error, $\varepsilon_{\text {nit }}$, such that

$$
U_{\text {nit }}=V_{\text {nit }}+\varepsilon_{\text {nit }}
$$

The deterministic utility is assumed to be a linear function of observed attributes. Hence, the utility function may be expressed as

$$
U_{n i t}=\beta_{i o}+\sum_{k=1}^{K} \beta_{k} x_{n i k t}+\varepsilon_{n i t}
$$

where $\beta_{k}$ is the parameter for attribute $k, x_{n i t}$ is an explanatory variable, related to attributes of the residence, job or transportation modes for commuting, and $\varepsilon_{n i t}$ is a random IID Gumbel distributed error term. We assume that individuals choose the multidimensional alternative that maximizes their utility.

We introduce various sources of preference heterogeneity in the model. First, we assume that people differ in terms of taste parameters $\beta_{k}$. In part, the unobserved heterogeneity in taste 
parameters can be accounted for by differences in socio-demographics, and in part there is pure error. Thus,

$$
\beta_{n k}=\bar{\beta}_{k}+\sigma_{k}+\sum_{m=1}^{M} \theta_{k m} z_{n m}, k=1, \ldots, K
$$

where $\bar{\beta}_{k}$ is the mean of the random parameter of attribute $k . z_{n m}$ is the $m$ th sociodemographic characteristic of individual $n, \theta_{k m}$ is a parameter to be estimated, and $\sigma_{k}$ denotes the standard deviation of random parameter $\beta_{n k}$. Then, the utility expression becomes

$$
U_{n i t}=\beta_{i o}+\sum_{k=1}^{K}\left(\bar{\beta}_{k}+\sigma_{k}+\sum_{m=1}^{M} \theta_{k m} z_{n m}\right) x_{n i k t}+\varepsilon_{n i t}
$$

Our experiment induced respondents to choose among three long-term life trajectory decisions, i.e. status quo (keep current), move house or change job. To allow for the possibility that unobserved heterogeneity underlying the choice of these long-term decisions may affect preferences for transportation modes, we additionally allow for three additional error components in each nested alternative, defined by the outcome of the long-term decision. The error components, $Q_{n 1}, Q_{n 2}$ and $Q_{n 3}$, denote the grouped error component of keep current, move house and change job. Thus, the utility function becomes

Status quo:

$$
U_{n 1 t}=\beta_{1 o}+\sum_{k=1}^{K}\left(\bar{\beta}_{k}+\sigma_{k}+\sum_{m=1}^{M} \theta_{k m} z_{n m}\right) x_{n 1 k t}+\lambda_{1} Q_{n 1}+\varepsilon_{n 1 t}
$$

Move house :

$$
\begin{aligned}
& U_{n 2 t}=\beta_{2 o}+\sum_{k=1}^{K}\left(\bar{\beta}_{k}+\sigma_{k}+\sum_{m=1}^{M} \theta_{k m} z_{n m}\right) x_{n 2 k t}+\lambda_{2} Q_{n 2}+\varepsilon_{n 2 t} \\
& \ldots \\
& U_{n 6 t}=\beta_{6 o}+\sum_{k=1}^{K}\left(\bar{\beta}_{k}+\sigma_{k}+\sum_{m=1}^{M} \theta_{k m} z_{n m}\right) x_{n 6 k t}+\lambda_{2} Q_{n 2}+\varepsilon_{n 6 t}
\end{aligned}
$$

Change job :

$$
\begin{aligned}
& U_{n 7 t}=\beta_{7 o}+\sum_{k=1}^{K}\left(\bar{\beta}_{k}+\sigma_{k}+\sum_{m=1}^{M} \theta_{k m} z_{n m}\right) x_{n 7 k t}+\lambda_{3} Q_{n 3}+\varepsilon_{n 7 t} \\
& \ldots \\
& U_{n 11 t}=\beta_{11 o}+\sum_{k=1}^{K}\left(\bar{\beta}_{k}+\sigma_{k}+\sum_{m=1}^{M} \theta_{k m} z_{n m}\right) x_{n 11 k t}+\lambda_{3} Q_{n 3}+\varepsilon_{n 11 t}
\end{aligned}
$$


We assume that these error components $Q_{n 1}$ are independent and follow a standard normal distribution, with $Q_{n 1} \sim N[0,1]$. $\lambda_{l}$ is a parameter to be estimated for the error component $l$.

Finally, we specify the variance heterogeneity of the error component as

$$
\operatorname{Var}\left[Q_{n 1}\right]=\left[\lambda_{l} \exp \sum_{m=1}^{M} \tau_{l m} z_{n m}\right]^{2}
$$

where $\tau_{l m}$ is a parameter that needs to be estimated.

The conditional choice probabilities then take on the logit form:

$$
p_{n t}\left(i \mid \boldsymbol{Q}_{n}\right)=\frac{\exp \left(\beta_{i o}+\sum_{k=1}^{K}\left(\bar{\beta}_{k}+\sigma_{k}+\sum_{m=1}^{M} \theta_{k m} z_{n m}\right) x_{n i k t}+\lambda_{l} Q_{n 1}\right)}{\sum_{i=1}^{I} \exp \left(\beta_{i o}+\sum_{k=1}^{K}\left(\bar{\beta}_{k}+\sigma_{k}+\sum_{m=1}^{M} \theta_{k m} z_{n m}\right) x_{n i k t}+\lambda_{l} Q_{n 1}\right)}
$$

Conditioned on the error components, the unconditional probability of a choice for alternative $i$ for individual $n$ is

$$
p_{n i t}=\int_{\boldsymbol{E}_{n}}\left(p_{n t}\left(i \mid \boldsymbol{Q}_{n}\right) f\left(\boldsymbol{Q}_{n l}\right)\right) d \boldsymbol{Q}_{n l}
$$

Integrate the taste variation of random parameter $\beta_{n k}$, the unconditional choice in Eq. (7) denotes as

$$
p_{n i t}=\int_{\boldsymbol{Q}_{n l}} \int_{\boldsymbol{\beta}_{n}}\left(\left(P_{n i t} \mid \boldsymbol{Q}_{n l}, \boldsymbol{\beta}_{n}\right) f\left(\boldsymbol{Q}_{n l}, \boldsymbol{\beta}_{n} \mid z_{n}\right)\right) d \boldsymbol{Q}_{n l} d \boldsymbol{\beta}_{n}
$$

In our experiment, respondents provide responses. If we ignore the repeated measurement nature of the data, biased parameter estimates may be produced. Furthermore, the model will underestimate the standard errors of the parameters, thus t-values will be inflated. In turn, this may lead researchers to falsely decide some effects are significant for the current sample size. Thus, we estimated these panel effects. Consequently, the full loglikelihood function can be written as follows

$$
L L=\sum_{n=1}^{N} \log \int_{\boldsymbol{Q}_{n l}} \int_{\boldsymbol{\beta}_{n}} \prod_{t=1}^{T}\left(\left(P_{n i t} \mid \boldsymbol{Q}_{n l}, \boldsymbol{\beta}_{n}\right) f\left(\boldsymbol{Q}_{n l}, \boldsymbol{\beta}_{n} \mid z_{n}\right)\right) d \boldsymbol{Q}_{n l} d \boldsymbol{\beta}_{n}
$$

\section{Analysis and results}

Table 3 presents the results of the error component mixed logit model (Model 2) and the base model with random parameters only (Model 1). Because we have a large number of attributes, it is unrealistic for the given sample size to estimate random effects for all attributes. From a behavioral point of view, understanding and modeling residential and work location choice behavior is a primary concern for urban planners, policymakers, and researchers (Schirmer et al. 2014; Dubernet and Axhausen 2016). Thus, residential and 


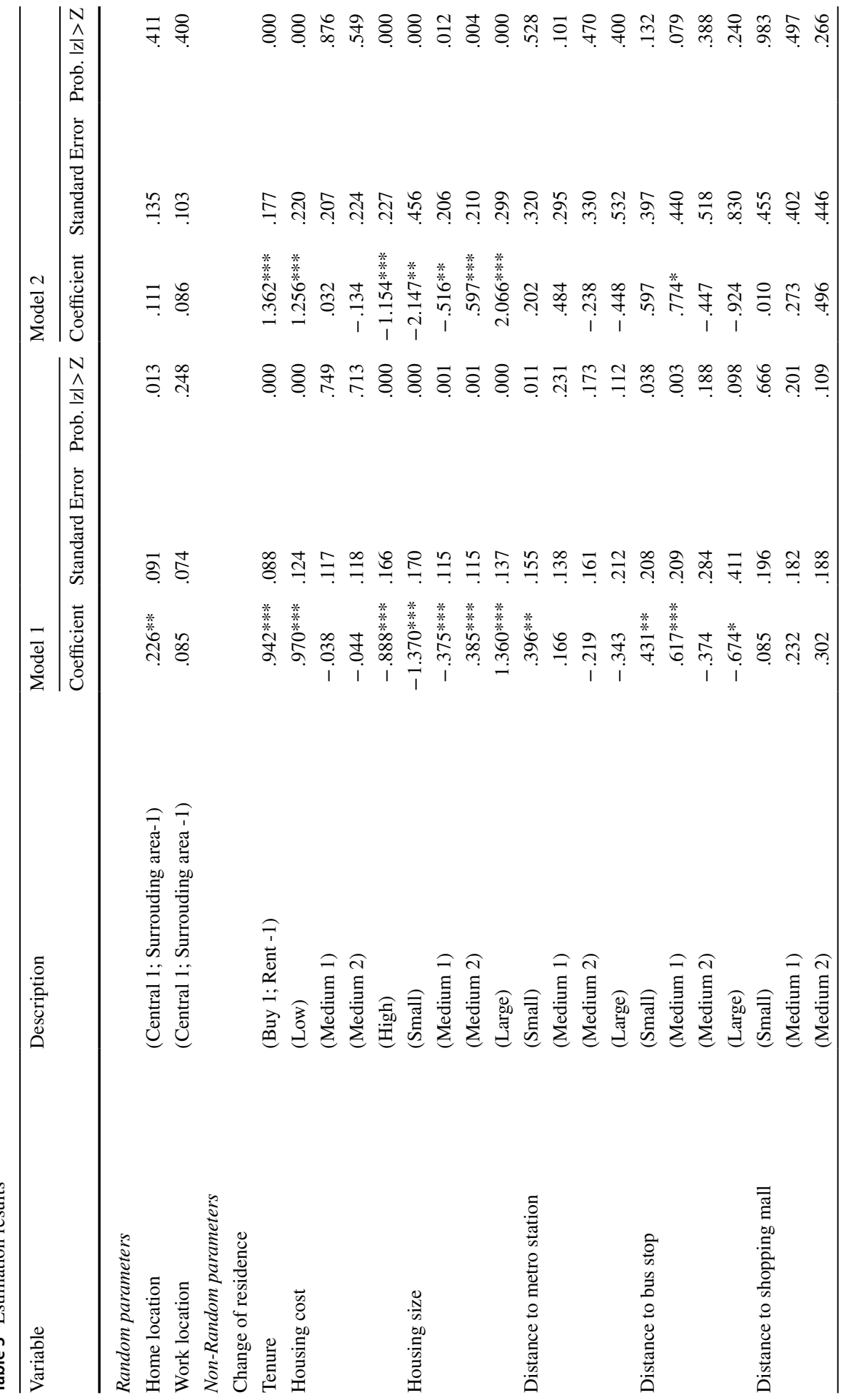




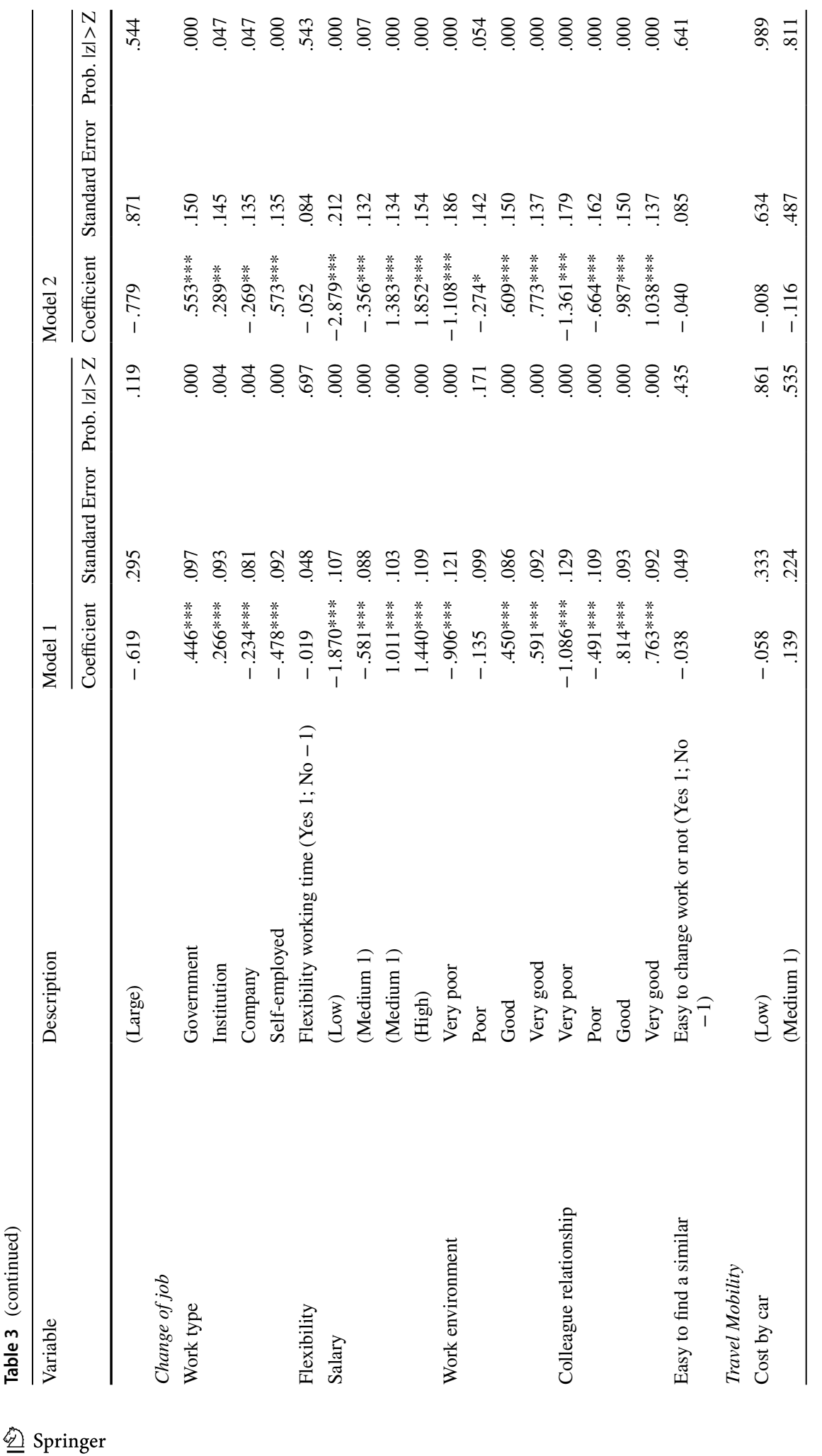




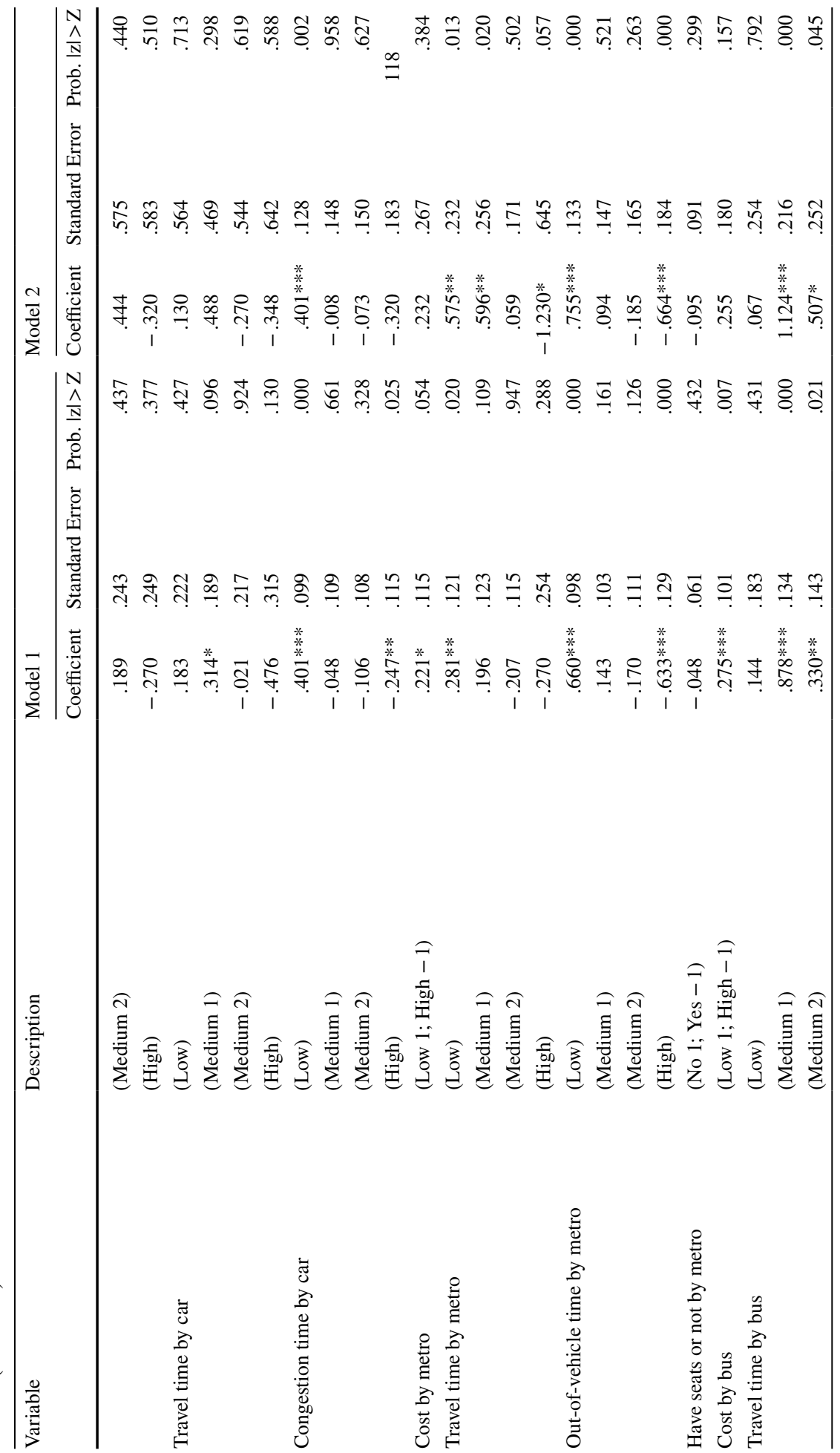




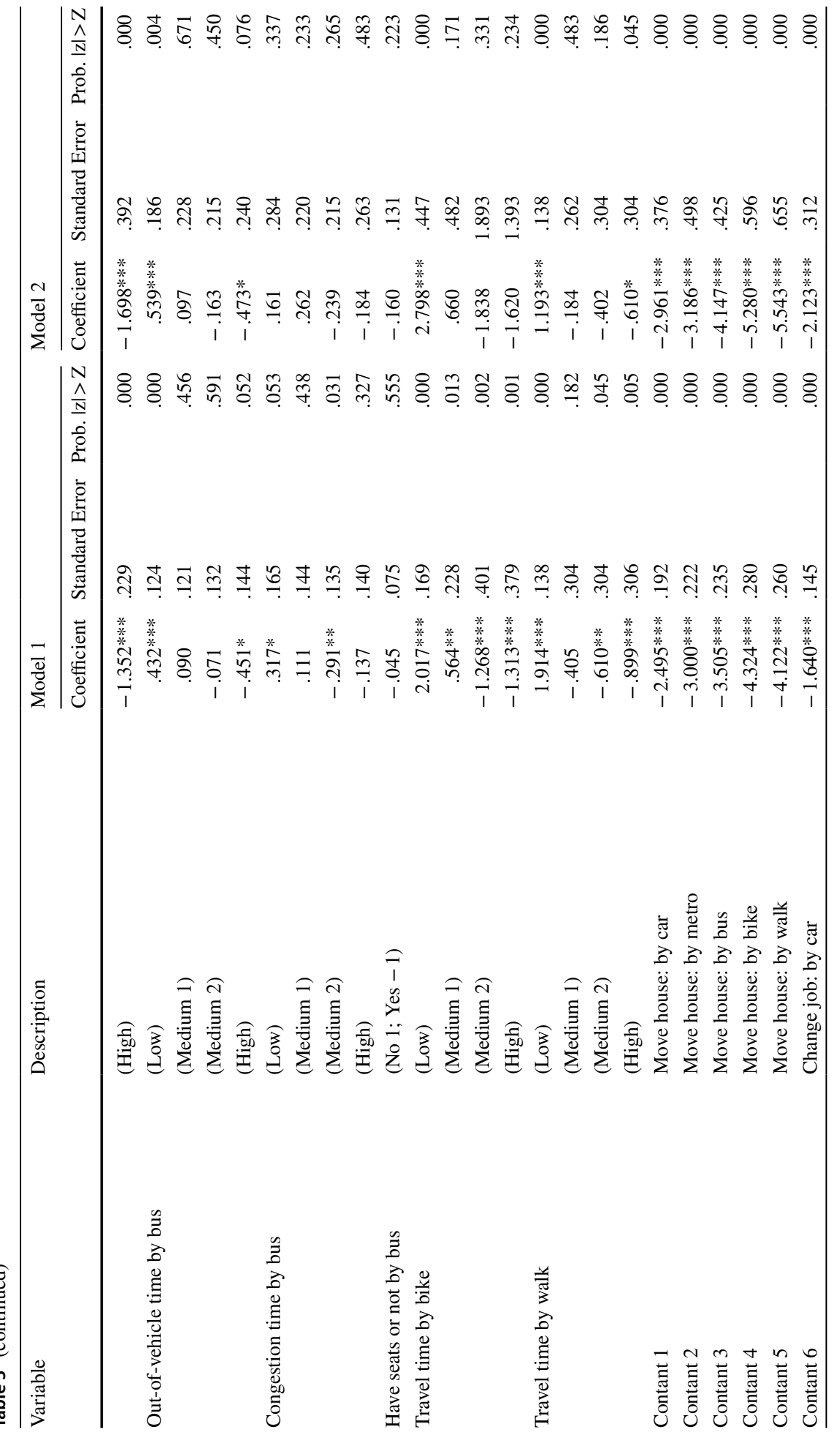




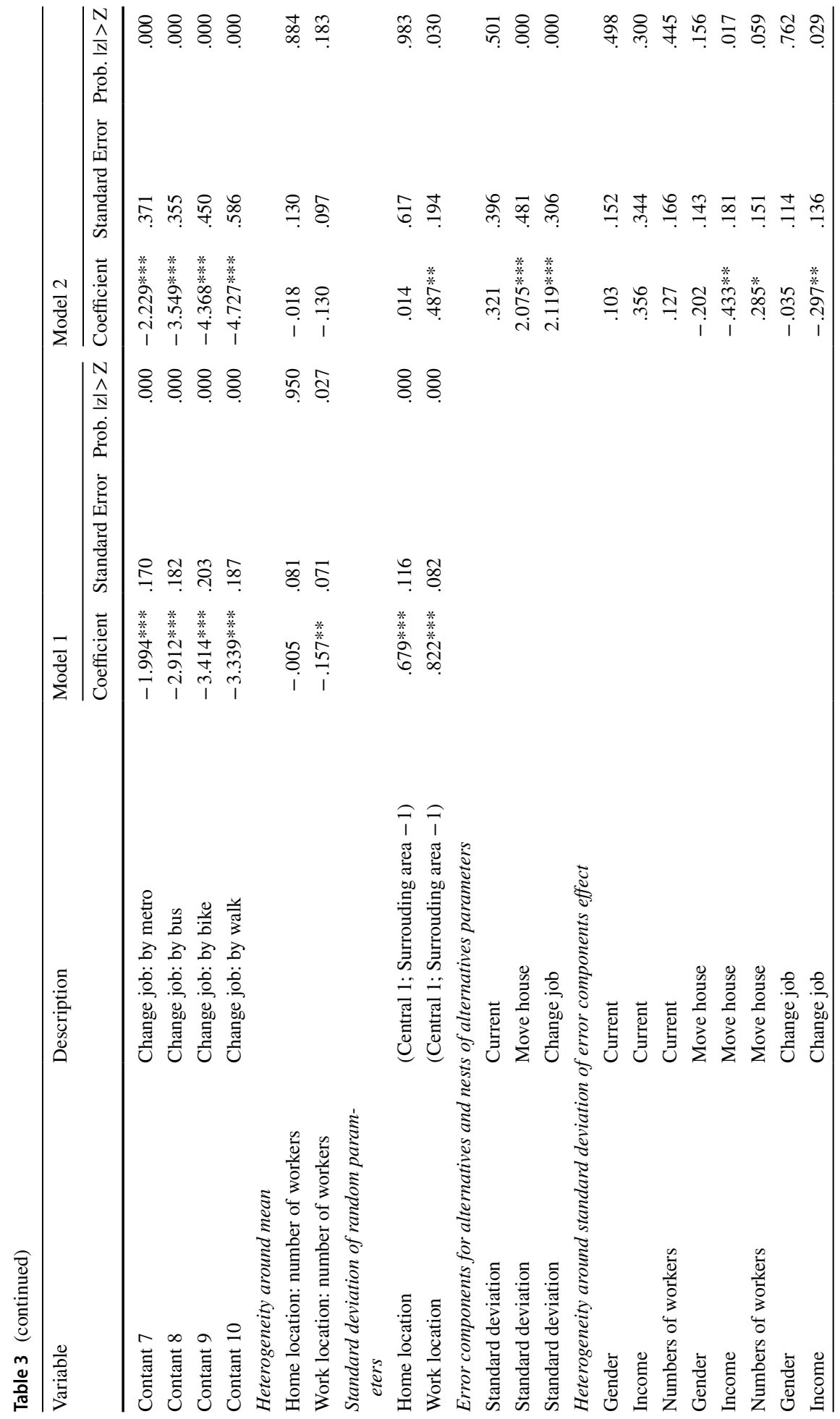




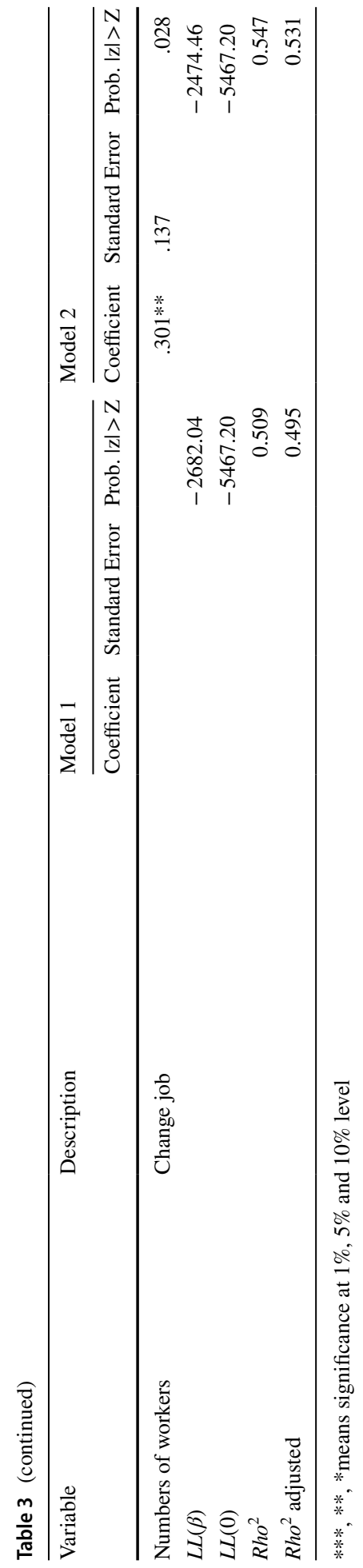

Springer 
work location were selected as the random attributes. In addition, not only the main effects but also several socio-demographic interaction effects were estimated in this study.

Nlogit software was used to estimate the error component mixed logit model. Both random variables and error components were assumed with a normal distribution. To get a stable estimate, we systematically checked the convergence of the parameter estimates from 100 to 5000 random Halton draws. The final estimates reported in this study are based on 500 Halton draws since increasing the number of draws did not improve the estimates.

Overall, the estimated error component logit model has a good fit. The log-likelihood $(L L)$ increased from -5467.20 to -2474.46 . The error component model improves the adjusted Rho-squared from 0.495 for the base random parameter model to 0.531 .

Results in Table 3 indicate that parameter signs for both the error component mixed logit model and base random parameter model are almost the same. Additionally, compared with the base random parameter mixed logit model, attributes were found less statistically significant for the error component mixed logit model. Since the error component mixed logit model performs better than the base mixed logit model, we discuss the results by focusing mainly on the error component model.

\section{Change of residence}

Overall, in the majority of situations respondents indicate to keep their current residence, suggesting that that everything else being equal, individuals/households prefer not to move house. This is as expected as that the process of changing residence is relatively costly and takes a lot of effort (buying and selling house, removal of furniture, and redecoration of the new home, etc.). Moreover, once settled and satisfied with their housing situation, individuals/households tend not to move any longer (Fischer and Malmberg 2001). Only if the increase in benefits from a new residence outweights the cost of relocating, a household is expected to relocate. Moreover, compared to changing jobs, the threshold to move house is relatively high which indicates that, as a long-term decision, people consider residential relocation more carefully and less easy. In addition, all housing-related attributes (tenure, monthly costs, housing size) are statistically significant for the moving house decision, while the effects of location and neighborhood-related attributes on the relocate decision are relatively small.

According to the results, the signs of the housing-related variables are consistent with the preceding expectations. Tenure is found to have a significant influence on the utility of residential relocation, the positive sign indicating that people prefer to buy their own house rather than rent one. Moreover, extreme high/low sales prices or rental costs have a substantial impact on a household's decision to move. In other words, extremely high housing cost, subject to their budget constraint, may cause owners and tenants to move house. Effects of house size are compelling, as well, supporting the previous literature and confirming that households prefer to have more living space when relocating.

For the built environment factors, previous studies have evaluated how accessibility affects location choice. As reported in several studies, proximity to local public transport stops (bus, tram, subway) is of relevance to residents. For example, Van de Vyvere et al. (1998) reported a positive effect of proximity to bus stops. In addition, other studies found that households prefer locations that provide greater accessibility to shopping (Bhat and Guo 2004). In line with the previous findings, our results show that the distance to bus stop has a significant effect on residential location decision. In addition, some studies showed that households prefer not to reside in the centre of cities (Kim et al. 2003; Vega 
and Reynolds-Feighan 2009, etc.), while other studies reported the opposite findings (Bhat and Guo 2004; Pinjari et al. 2007). This difference may be due to the fact that the effect of residential location differs between population groups. For instance, Zondag and Pieters (2005) differentiated between household types in the Netherlands and reported that singleearner households favour urban living, while households with children prefer to live in suburban environments. In the current study, we found that central city is more attractive than the surrounding areas. The negative sign of the interaction between residential location and numbers of workers in the household suggests that households with more than one worker have a higher preference to work in the central city. However, these estimates are not statistically significant.

\section{Change of job}

Here also, the vast majority of the choices result in keeping the current job. People prefer not to change job frequently may due to the mental costs (i.e. the necessity to learn a new job, familiarize oneself with new colleagues and the new institution, etc.) associated with changing jobs. However, compared to moving house, the relative low alternative-specific constant indicates that the cost of changing job is relatively small.

For the variable job type, the results show that individuals prefer government and public institutions to company and self-employed. This is understandable because government organizations and public institutions generally display a relative high degree of job security, a good work-family balance, and a fair and stable wage (Lewis and Frank 2002). As important predictors of job choice, the effects of a high salary, good co-worker relationship and work environment are significant. This means people consider not only salary, but also work environment and harmony in colleague communications. Company policies, which enhance the work relationships and improve the work environment, reduce the chance of changing job.

In case of other influencial attributes, little compelling evidence is found that 'having flexible working hours' and 'easy to find a similar job or not' plays a role in job change. Similarly, the geographic location factor does not seem an influential factor in job decisionmaking. Moreover, we estimated the effect of numbers of workers on work location preference. The negative sign suggests that households with more than one worker care more about working in the central city. However, this effect is not statistically significant.

\section{Travel mobility}

As for transportation mode preferences, time-related variables representing an increase in commuting time, congestion time and out-of-vehicle time influence the likelihood of mobility change. Many previous studies reported that excessive commuting time has a significant negative impact on the utility of different transportation modes for the journey to work (e.g., Guo and Bhat 2007; Zhou and Kockelman 2008; Habib and Miller 2009; Lee and Waddell 2010). As expected, according to our results, commuting time is negatively associated with mobility change, suggesting that individuals generally try to locate close to work. Differentiating in commuting time by car, public transport and non-motorized modes, commuting time is shown as an influential factor but with a different level of significance. For the public transportation and non-motorized modes, we observe a significant impact on choice probability, while the commuting time for the car mode is not significant. Such findings may be useful to city planners and policy makers to encourage people working or living in close proximity 
to avoid excess commuting time. A long commuting time by public and slow transportation modes may increase motorization and lead to a higher propensity of car ownership. In addition, although not all attributes are significant, results pertaining to congestion time and outof-vehicle time of different transportation modes suggest these two factors influence people's choice behavior. Form a policy point of view, these results indicate the importance of improving accessibility of bus stops and metro stations and reducing congestion time for public transportation modes.

The value of travel time (VoT) is often used in applied transport studies. In most cases, VoT is estimated in the context of short-term decisions such as route and mode choice. In longer term settings which involve changes in residential or employment locations, people may tradeoff between the travel time and travel cost. In the context of co-dependent choices, we calculated the values of time as shown in Table 4. The estimated value of travel time is $27.84 \mathrm{CNY}$ per hour (or $3.76 € / \mathrm{h}$ ) for car, 2.22 CNY per hour $(0.3 € / \mathrm{h}$ ) for metro and $15.36 \mathrm{CNY}$ per hour $(2.1 € / \mathrm{h})$ for bus. Although these values are smaller than the average of the studies on shortterm decisions, they are in line with pevious research based on the long-term context (Pérez et al. 2003; Kim et al. 2005; Tillema et al. 2010; Peer et al. 2015; Dubernet and Axhausen 2016; Beck et al. 2017). Furthermore, as indicated by a relatively lower value of time, the travel time appears to play a less important role in the context of long-term decisions.

Estimates of the alternative-specific constants indicate that respondents on average prefer private transport over than other commuting modes. Furthermore, metro is more attractive than bus. Preferences for slow modes (bicycle and walk) are similar. Moreover, results show that nonlinear effects are found for several travel-related attributes, such as cost by car, travel time and congestion time by bus.

\section{Explanation of error components}

Results of the three alternative-specific error components (keep current, move house or change job) show that the standard deviation of moving house and changing job are statistically significant. It suggests that unobserved heterogeneity exists in preferences for transportation modes, dependent upon moving house and changing work decisions that are not fully captured by the alternative-specific parameter estimates of the attributes of the different transportation modes. This evidence indicates that a 'nested structure' exists in the process of transportation mode choice when people decide to move house and change job. Furthermore, we allowed for heteroscedasticity in the variance of the error components as a function of sociodemographics. Because the number of parameters relative to sample size does not invite estimating too many interaction effects, after exploring different combinations of socio-demographic variables, as listed in Table 3, gender, income and numbers of workers in the households were taken into consideration.

In case of moving house, the negative value of income indicates that as income decreases, the standard deviation of the error component decreases as well, leading to a reduction in preference htetrogeneity from these unobserved effects for individuals with higher salary when they decide to move house. Morever, number of workers in the household shows a significant effect on the heterogeneity of moving house. Specifically, results indicate that households with

Table 4 Value of time of different transportation modes

\begin{tabular}{llll}
\hline Mode & Car & Metro & Bus \\
\hline VoT $(\mathrm{CNY} / \mathrm{h})$ & 27.84 & 2.22 & 15.36 \\
\hline
\end{tabular}


single workers are more heterogeneous when they decide to move house. Similarly, as to job choice, income and numbers of workers in the household have a significant influence on preference heterogeneity for this long-term decision. Our result shows that as the income and/or number of workers increases, the standard deviation of the error component decreases, implying a reduction in preference heterogeneity in these unobserved effects.

\section{Conclusions and discussion}

Life-trajectories are critical in understanding individuals' activity-travel behavior. The modeling and prediction of transportion mode choice depends on long-term life choices. However, few studies have reported individuals' preferences for the interdepent choice of house, job and transportation mode. Ignoring the effects of any long-term key life events may lead to biased estimation results and therefore misleading policy recommendations or assessment of policy impacts.

In order to fill this research gap, this study estimated a multi-dimensional choice model related to residential, job and transportation mode choice for commute trips using a pivoted stated choice experiment. In addition to estimating the part-worth utilities of the attribute levels defining the three choice dimensions, the estimated error components mixed logit model allows estimating the effects of various sources of observed and unobserved heterogeneity on the utility of the multi-dimensional choice profiles and the corresponding choice probabilities.

Results show that not only the random parameters but also the variances associated with the long-term alternative-specific error components are significant. The specified error components for the long-term decisions are significant, indicating that unobserved heterogeneity exists between relocation and transportation mode choice, which is not fully captured by the alternative specific attributes of transportation modes.

Although significant interdependencies between different life domains have been found in this study, it still needs to further investigate the long-term mobility decisions from a longitudinal perspective. Most life course decisions are dynamic in nature, one mobility decisios may increase the need/desire of mobility decision in other life domain. As a nature extension to the current study, more long-term life events as well as the duration for life course mobility decisions might be taken into consideration. Moreover, in order to avoid the choice experiment is over complex, the model in the current study is built based on the assumption that people will not change transportation modes only nor both houses or jobs simultaneously, but either change house or change job. We acknowledge that this assumption may not be strictly hold in actual situations since people may unavoidably change transportation mode only, and in rare cases both house and job with or without a time lag. It might be necessary to study exclusive choice options especially when the focus is more on the aspect of market shares.

Acknowledgements This research was supported by the China Scholarship Council (China). We would like to thank the China Scholarship Council for providing the funding for the Ph.D. study.

\section{Compliance with ethical standards}

Conflict of interest The authors declared that they have no conflict of interest. 
Open Access This article is distributed under the terms of the Creative Commons Attribution 4.0 International License (http://creativecommons.org/licenses/by/4.0/), which permits unrestricted use, distribution, and reproduction in any medium, provided you give appropriate credit to the original author(s) and the source, provide a link to the Creative Commons license, and indicate if changes were made.

\section{References}

Bagley, M.N., Mokhtarian, L.P., Kitamura, R.: A methodology for the disaggregate, multidimensional measurement of residential neighborhood type. Urban Stud. 39(4), 689-704 (2002)

Balbontin, C., Ortúzar, J., Swait, J.D.: A joint best-worst scaling and stated choice model considering observed and unobserved heterogeneity: an application to residential location choice. J. Choice Model. 16, 1-14 (2015)

Beck, M.J., Hess, S., Cabral, M.O., Dubernet, I.: Valuing travel time savings: a case of short-term or long-term choices? Transp. Res. E 100, 133-143 (2017)

Bhat, C.R.: Incorporating observed and unobserved heterogeneity in urban work travel mode choice modeling. Transp. Sci. 34(2), 228-238 (2000)

Bhat, C.R., Guo, J.Y.: A mixed spatially correlated logit model: formulation and application to residential choice modeling. Transp. Res. B 38, 147-168 (2004)

Bhat, C.R., Guo, J.Y.: A comprehensive analysis of built environment characteristics on household residential choice and auto ownership levels. Transp. Res. B 41(5), 506-526 (2007)

Dargay, J.: The effect of income on car ownership: evidence of asymmetry. Transp. Res. A 35(9), 807821 (2001)

Dargay, J., Hanly, M.: Volatility of car ownership, commuting mode and time in the UK. Transp. Res. A 41(10), 934-948 (2007)

DeSalvo, J.S., Huq, M.: Mode choice, commuting cost, and urban household behavior. J. Reg. Sci. 45(3), 493-517 (2005)

Dubernet, I., Axhausen, K.: The choice of workplace and residential location in Germany. In: 16th Swiss Transport Research Conference (STRC 2016), Ascona, Switzerland (2016)

Ettema, D.: The impact of telecommuting on residential relocation and residential preferences: a latent class modeling approach. Transp. Land Use 3(1), 7-24 (2010)

Grava, S.: Urban Transportation Systems: Choices for Communities. McGraw-Hill, New York (2003)

Greene, W., Hensher, D.A.: Heteroscedastic control for random coefficients and error components in mixed logit. Transp. Res. E 43(5), 610-623 (2007)

Guerra, E.: Has Mexico City's shift to commercially produced housing increased car ownership and car use? J. Transp. Land Use 8(2), 171-189 (2015)

Guo, J.Y., Bhat, C.R.: Operationalizing the concept of neighbourhood: application to residential location choice analysis. Transp. Geogr. 15(1), 31-45 (2007)

Fischer, P., Malmberg, G.: Settled people don't move: on life course and (im) mobility in Sweden. Int. J. Popul. Geogr. 7, 357-371 (2001)

Habib, M.A., Miller, E.J.: Reference-dependent residential location choice model within a relocation context. Transp. Res. Rec. J. Transp. Res. Board 2133(1), 92-99 (2009)

Handy, S., Cao, X., Mokhtarian, P.: Correlation or causality between the built environment and travel behavior? Evidence from Northern California. Transp. Res. D 10(6), 427-444 (2005)

Heinen, E., Maat, K., Wee, B.: The effect of work-related factors on the bicycle commute mode choice in The Netherlands. Transportation 40(1), 23-43 (2013)

Hensher, D., Greene, W.: The mixed logit model: the state of practice. Transportation 30(2), 133-176 (2003)

Khattak, A.J., Rodriguez, D.: Travel behavior in neo-traditional neighbourhood developments: a case study in USA. Transp. Res. A 39, 481-500 (2005)

Kim, J.H., Pagliara, F., Preston, J.: An analysis of residential location choice behavior in Oxfordshire, UK: a combined stated preference approach. Int. Rev. Public Adm. 8(1), 103-114 (2003)

Kim, J.H., Pagliara, F., Preston, J.: The intention to move and residential location choice behavior. Urban Stud. 42(9), 524-544 (2005)

Lee, B., Waddell, P.: Residential mobility and location choice: a nested logit model with sampling of alternatives. Transportation 37(4), 587-601 (2010)

Lerman, S.R.: Location, housing, automobile ownership and mode to work: a joint choice model. Transp. Res. Rec. J. Transp. Res. Board 610, 6-11 (1976) 
Lewis, G.B., Frank, S.A.: Who wants to work for the government? Public Adm. Rev. 62(4), 395-404 (2002)

Louviere, J., Timmermans, H.J.P.: Hierarchical information integration applied to residential choice behavior. Geogr. Anal. 22(2), 127-144 (1990)

Meixell, M.J., Norbis, M.: A review of the transportation mode choice and carrier selection literature. J. Logist. Manag. 19(2), 183-211 (2008)

Meyer, R.J., Levin, I.P., Louviere, J.J.: Functional analysis of mode choice. Transp. Res. Rec. 673, 1-7 (1978)

$\mathrm{Ng}$, C.F.: Commuting distances in a household location choice model with amenities. J. Urban Econ. 63(1), 116-129 (2008)

Paleti, R., Bhat, C., Pendyala, R.: An integrated model of residential location, work location, vehicle ownership, and commute tour characteristics. Transp. Res. Rec. J. Transp. Res. Board 2382, 162172 (2012)

Paulssen, M., Temme, D., Vij, A., Walker, J.: Values, attitudes and travel behavior: a hierarchical latent variable mixed logit model of travel mode choice. Transportation 41(4), 873-888 (2014)

Peer, S., Verhoef, E.T., Knockaert, J., Koster, P., Teseng, Y.Y.: Long-run versus short-run perspectives on consumer schedeling: evidence from a revealed-preference experiment among peak-hour road commuters. Int. Econ. Rev. 56(1), 303-323 (2015)

Pérez, P.E., Martínez, F.J., Ortúzar, J.D.D.: Microeconomic formulation and estimation of a residential location choice model: implications for the value of time. J. Reg. Sci. 43(4), 771-789 (2003)

Pinjari, A., Pendyala, R., Bhat, C., Waddell, P.: Modeling residential sorting effects to understand the impact of the built environment on commute mode choice. Transportation 34(5), 557-573 (2007)

Pinjari, A., Pendyala, R., Bhat, C., Waddell, P.: Modeling the choice continuum: an integrated model of residential location, auto ownership, bicycle ownership, and commute tour mode choice decision. Transportation 38(6), 933-958 (2011)

Quarmby, D.A.: Choice of travel mode for the journey to work: some findings. J. Transp. Econ. Policy 1(3), 273-314 (1967)

Rashidi, T.H., Mohammadian, A., Koppelman, F.S.: Modeling interdependencies between vehicle transaction, residential relocation and job change. Transportation 38(6), 909-932 (2011)

Rich, J., Nielsen, O.: A microeconomic model for car ownership, residence and work location. In: European Transport Conference, PTRC, Cambridge, UK (2001)

Rodriguez, D.A., Joo, J.: The relationship between non-motorized mode choice and the local physical environment. Transp. Res. D 9(2), 151-173 (2004)

Salon, D.: Cars and the city: an investigation of transportation and residential location choices in New York City. Dissertation, University of California (2006)

Salon, D.: Neighborhoods, cars, and commuting in New York City: a discrete choice approach. Transp. Res. A 43, 180-196 (2009)

Scheiner, J., Holz-Rau, C.: Changes in travel mode use after residential relocation: a contribution to mobility biographies. Transportation 40(2), 431-458 (2013)

Schirmer, P.M., Van Eggermond, M., Axhausen, K.W.: The role of location in residential location choice models: a review of literature. Transp. Land Use 7(2), 3-21 (2014)

Schwanen, T., Mokhtarian, P.L.: What affects commute mode choice: neighbourhood physical structure or preferences toward neighborhoods? Transp. Geogr. 13(1), 83-99 (2005a)

Schwanen, T., Mokhtarian, P.L.: What if you live in the wrong neighbourhood? The impact of residential neighbourhood type dissonance on distance traveled. Transp. Res. D 10(2), 127-151 (2005b)

Tillema, T., Van Wee, B., Ettema, D.: The influence of (toll-realted) travel costs in residential location decisions of households: a stated choice approach. Transp. Res. A 44, 752-796 (2010)

Timmermans, H.J.P., Borgers, A.W.J., Van Dijk, J., Oppewal, H.: Residential choice behaviour of dual earner households: a decompositional joint choice model. Environ. Plan. A 24(4), 517-533 (1992)

Train, K.: Discrete Choice Methods with Simulation. Cambridge University Press, Cambridge (2003)

Tran, T.M., Zhang, J., Chikaraishi, M., Fujiwara, A.: A joint analysis of residential, work location and commuting mode choice in Hanoi, Vietnam. Transp. Geogr. 54, 181-193 (2016)

Van der Waerden, P.J.H.J., Timmermans, H.J.P., Borgers, A.W.J.: The influence of key events and critical incidents on transport mode choice switching behaviour: a descriptive analysis. In: 10th International Conference on Travel Behaviour Research (2003)

Van de Vyvere, Y., Oppewal, H., Timmermans, H.J.P.: The validity of hierarchical information integration choice experiments to model residential preference and choice. Geogr. Anal. 30(3), 254-272 (1998)

Van Ommeren, J.: Job moving, residential moving, and commuting: a search perspective. J. Urban Econ. 46, 230-253 (1999) 
Vega, A., Reynolds-Feighan, A.: A methodological framework for the study of residential location and travel-to-work mode choice under central and suburban employment destination patterns. Transp. Res. A 43(4), 401-419 (2009)

Walker, J., Li, J.: Latent lifestyle preferences and household location decisions. J. Geogr. Syst. 9(1), 77-101 (2007)

Zhou, B.B., Kockelman, K.M.: Microsimulation of residential land development and household location choices: bidding for land in Austion, Texas. Transp. Res. Rec. J. Transp. Res. Board 2077(1), 106-112 (2008)

Zondag, B., Pieters, M.: Influence of accessibility on residential location choice. Transp. Res. Rec. J. Transp. Res. Board 1902, 63-70 (2005)

Jia Guo is a PhD candidate in Urban Planning Group of the Eindhoven University of Technology. She is majoring in various topics related to urban planning. Her current research is mainly focused on travel behavior analysis, transportation planning, residential location choice, life-oriented research and household longterm decisions.

Dr. Tao Feng is an Assistant Professor in Eindhoven University of Technology. His main research field is transportation where he looks into various topics relating to travel demand forecasting, travel behaviour analysis, (big) data and travel surveys. He is the associated editor of journal Asia Transport Studies. He serves on committee members for several international conferences and reviewer for many journals/conferences. His research funding are related to big data, energy and transportation within the smart city program.

Harry J. P. Timmermans is Head of the Urban Planning Group of the Eindhoven University of Technology, the Netherlands. He has research interests in modeling decision-making processes and decision support systems in a variety of application domains, including transportation. He is editor of the Journal of Retailing and Consumer Services, and serves on the board of several other journals in transportation, geography, urban planning, marketing, artificial intelligence and other disciplines. He is Co-chair of the International Association of Travel Behavior Research (IATBR), and member of several scientific committees of the Transportation Research Board. He has also served as member of conference committees in transportation and artificial intelligence. 